\title{
Dr. Luis De Santis (1914-2000)
}

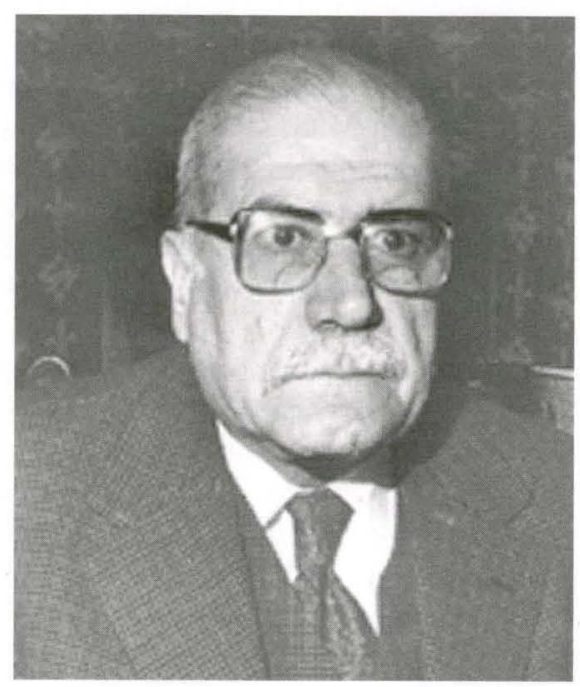

Com la desaparición fisica del Dr. Luis De Santis, acaecida el 02 de agosto de 2000, a los 86 años de edad, la Entomología Argentina, pierde a uno de sus más altos referentes y a un maestro de varias generaciones de entomólogos.

El Dr. De Santis cursó estudios superiores en la Universidad Nacional de La Plata, obteniendo los títulos de Ingeniero Agrónomo y Doctor en Ciencias Naturales. En esta Casa de estudios ocupó entre otros cargos los de Profesor Titular, Jefe de Departamento, Vicedecano y Decano y desde febrero de 1979 a diciembre de 1983 el de Director del Museo de La Plata. Se desempeñó además como Consejero Académico y Miembro del Consejo Superior de la Universidad Nacional de La Plata. Actualmente se desempeñaba como Profesor Emérito de la Facultad Nacional de Ciencias Naturales y Museo.

Fue Miembro de Número de las Academias Nacionales de Ciencias de Buenos Aires y de Agronomía y Veterinaria, Miembro Activo de la Academia de Ciencias de Nueva York, Miembro Activo de la Associación Americana para el Progreso de las Ciencias de Washington, Miembro de Honor de la Fundación Miguel Lillo de San Miguel de Tucumán, Investigador Asociado del Department of Agriculture and Consumer Services of Gainesville (Florida, Estados Unidos), Investigador del CONICET, Socio Paul Harris de la Fundación Rotaria Internacional.

Zoólogo dedicado a la Entomología se especializó en el estudio de los microhimenópteros parasitoides y de los tisanópteros, acerca de los cuales há publicado más de 260 trabajos científicos en revistas especializadas nacionales e internacionales. Sus

Revta bras. Zool. 17 (3): 889 - 890. 2000 
obras sobre los Aphelinidae y Encyrtidae, microhimenópteros de gran valor como controladores biológicos y sus Catálogos de los Himenópteros Parasitoides de América del Sur, le han dado renombre mundial. No menos importantes son sus trabajos especiales sobre la fauna de Chalcidoideos de las Isla de Tierra del Fuego, Juan Fernández, San Ambrosio, Fernando de Noronha y Madagascar. Asimismo há sido autor de numerosos trabajos didácticos y de divulgación.

Sus relevantes antecedentes profesionales lo han hecho merecedor de premios y distinciones científicas y acedémicas, nacionales y extranjeras: Premio Irineo Cucullú otorgado por la Institución Mitre (1935), Premio Nacional de Ciencias Naturales y Biológicas (1948), Medalha de Oro otorgada por la Fundación Filippo Silvestre de la Universidad de Nápoles (1964), Premio Angel Gallardo (1973), Diploma al Mérito y Konex de Platino (1983), Galvano Recordatorio otorgado por el Insectario de La Cruz (Chile) por su colaboración por espacio de 50 años (1989), Premio Homero Manzi (1998).

Demonstraba una profunda vocación docente y gran generosidad para compartir sus conocimientos y experiencias, no solo com sus discípulos, sino com toda persona que se acercara a su despacho com alguna inquietud.

Su integridad y su extensa trayectoria científica lo convirtieron en consultor permanente de alumnos, investigadores e instituciones nacionales e internacionales. Como ser humano y como prefesional el Dr. De Santis deja una huella imborrable y su nombre seguirá vigente en el tiempo, no solo entre sus numerosos discípulos, sino en la comunidad científica en general. Quienes tuvimos el privilegio de formarnos a su lado lo recordaremos entrañablemente.

Marta S. Loiácono 